\title{
Chemical and sensory characterization of corn oil flavoured by citrus
}

\section{Caracterização química e sensorial do óleo de milho com sabor cítrico}

\author{
Petra Beatriz Navas Hernández ${ }^{1 *}$ (D), Armando Carrasquero Durán² (D) \\ ${ }^{1}$ Universidad Central de Venezuela, Facultad de Agronomía, Maracay- Venezuela \\ 2Universidad Pedagógica Experimental Libertador, Departamento de Química, City Maracay - Venezuela \\ ${ }^{*}$ Corresponding Author: Petra Beatriz Navas Hernández, Universidad Central de Venezuela, Facultad de \\ Agronomía, Departamento de Química y Tecnología, Apartado Postal 2579, Maracay Estado Aragua - Venezuela, \\ e-mail: navasbeatriz@gmail.com
}

Cite as: Navas Hernández, P. B., \& Carrasquero Durán, A. (2020). Chemical and sensory characterization of corn oil flavoured by citrus. Brazilian Journal of Food Technology, 23, e2019054. https://doi.org/10.1590/19816723.05419

\begin{abstract}
A commercial and refined corn oil was added with fresh lemon and orange fruits to produce corn oil flavoured (COF), which were characterized for their quality parameters, fatty acid profile and concentrations of minor components. The sensory analysis was performed by a panel using the quantitative descriptive analysis and the hedonic score. Results showed that the addition of citrus fruits did not affect the oil quality indices, accomplishing the requirements for commercialization. The biophenols and pigments, initially absent in the refined oil, were detected in COF. The addition of orange or lemon fruits to the corn oil had no effects on oil stability, while the volatile profile in the headspace of flavoured oils showed the presence of several terpenes that were originally absent, among them: limonene; $\gamma$-terpinene; $\alpha$-pinene and $\beta$-pinene. The sensory results confirmed that positive attributes and the acceptability of the unflavored corn oil can be improved by increasing amounts of both fruits.
\end{abstract}

Keyword: Aromatized oil; Citrus fruits; Sensory analysis; Volatiles.

\section{Resumo}

Óleo comercial de milho refinado foi adicionado com limão e laranja frescos para produzir óleos de milho aromatizados (FCO), que foram caracterizados por seus parâmetros de qualidade, perfil de ácidos graxos e concentrações menores de componentes. A análise sensorial foi realizada por um painel, utilizando a análise descritiva quantitativa e escala hedônica. Os resultados mostraram que a adição de frutas cítricas não afetou os índices de qualidade dos óleos, cumprindo os requisitos para comercialização. Os biofenóis e pigmentos inicialmente ausentes no óleo refinado foram detectados no FCO. A adição de laranja ou limão ao óleo de milho não teve efeito sobre a estabilidade do óleo, enquanto o perfil volátil no headspace dos óleos aromatizados mostrou a presença de diversos terpenos originalmente ausentes, dentre os quais o limoneno, o $\gamma$-terpineno e o $\alpha$ e $\beta$-pineno. Os resultados sensoriais confirmaram que os atributos positivos e a aceitabilidade do óleo de milho sem sabor podem ser melhorados pela adição de quantidades aumentadas de ambos os frutos.

Palavras-chave: Óleo aromatizado; Frutas cítricas; Análise sensorial; Voláteis. 


\section{Introduction}

Refined corn oil is one of the most important edible oils for many Latin American countries, whereas this oil is mostly used for frying and dressing. The solvent extraction is employed to obtain the virgin oil from the corn germ, which is a byproduct of the precooked flour industry. After this extraction, physical and chemical refining processes are applied to obtain a clear pale yellow oil with high proportion of polyunsaturated fatty acids (PUFAs) and natural tocopherols, such as vitamin E.

This edible oil does not present either the flavor or taste properties found in other vegetable oils, for instance in the virgin olive oil. Actually, there is a growing interest for the addition of herbs, different species or fruits with bioactive compounds (Foster et al., 2005) to the edible oils in order to improve their sensory, health and chemical stability, producing the called "flavoured", "aromatized" or "gourmet" oils.

Few studies have demonstrated the aromatization of corn oil. Among them, Navas (2016) found that corn oil can be aromatized with several species such as garden leek (Allium porrum), chives (Allium schoenoprasum), coriander (Coriandrum sativum) and black pepper (Piper nigrum), giving to the oil good sensory notes with high acceptability by consumers. Furthermore, the oxidative stability of corn oil under accelerated conditions was evaluated after adding onion, garlic and black tea (Navas et al., 2006), nevertheless, results showed that the extracts produced by these species effectively preserve the edible oil during long term storage.

Citrus fruits are recognized as a source of edible oils with complex mixtures of substances, including terpenes, sesquiterpenes and many oxygenated compounds, which may modify the sensory notes in these oils. Among the terpenes, the limonene is found in higher concentrations, followed by $\gamma$-terpinene, $\beta$-pinene and myrcene, these compounds may be the responsible for new taste and aromas in the aromatized oils (Issaoui et al., 2011).

In addition, lemon and orange contain many biophenolic compounds, such as the citrus flavonoids hesperidin and naringenin that possess potential antiradical properties (Pérez-Najera et al., 2013; Kelebek et al., 2009; Kuljarachanan et al., 2009). Studies on the addition of these compounds to the vegetable oils are necessary to establish their potential use in food systems as natural antioxidants or flavour additives.

The flavoured oils can be obtained by several ways, for instance, maceration, addition of essential oils, infusions etc., and these mean performing these procedures at home or even in a restaurant avoiding the use of industrial processed oils. In this way, the chefs may taste it until getting the ideal mixture according to their criteria and experience. Furthermore, the vast majority of culinary techniques use oils or fats as an element that may have impact on taste, texture and general characteristics of prepared foods, but also contribute to the calorie intake and provide vitamins and many important lipid soluble bioactive compounds for healthy diet.

The oils flavored with citrus fruits are excellent in culinary, also presenting organoleptic and healthy properties aimed to find new ways, techniques and flavours, seeing that edible oils could play a prominent role. These oils can be used in the restaurant to steam food, for instance, meat, fish or salads, however, "the chef decides what you eat" by creating delicious dishes and understanding food quality and perception. At the same time, it is necessary to consider the demand of the consumers, who judge the quality of a product according to the satisfaction of their personal taste.

In this work, aromatized oils were prepared with both citric fruits employing the maceration of whole fresh fruits in a commercial refined corn oil. The aromatized oils were evaluated in terms of their chemical composition, oxidation stability and sensory properties in order to propose their use in food systems. 


\section{Materials and methods}

\subsection{Chemicals and refined corn oil samples}

All reagents were of analytical grade. Authentic reference chemical compounds were obtained from Sigma-Aldrich (United States of America (USA)). Commercial and refined corn oil and citrus fruits (lemon (Citrus aurantifloria L.) and orange (Citrus sinensis L.)) were obtained from local commerce.

Samples of COF were produced as described herein: the whole mature fruits were washed with $0.1 \%$ sodium hypochlorite $(\mathrm{NaOCl})$, rinsed with distilled water, sliced with a knife of $1 \mathrm{~cm}$ width and treated with $3 \mathrm{~mL}$ of $1 \%$ sodium chloride $(\mathrm{NaCl})$ solution for $30 \mathrm{~min}$. The slices were dried by hand with a sheet of filter paper and adequate amounts of lemon or orange slices were immersed in the refined corn oil to obtain 3.0; 5.0 and $7.0 \mathrm{~g}$ of fruit in $100 \mathrm{~g}$ of edible oil (Treatments T1 to T6). Dark bottles (100 mL) were used in all cases with a headspace of less than $1 \mathrm{~cm}$ to prevent oil deterioration and stored at $25 \pm 2{ }^{\circ} \mathrm{C}$ in the darkness for one month. Finally the macerates were filtered through a qualitative filter paper and centrifuged at $3000 \mathrm{rpm}$ for $10 \mathrm{~min}$ to obtain a corn oil flavoured clear and free of residues.

\subsection{Sensory analysis}

The COF were characterized by sensory analysis performed using the quantitative descriptive analysis, based on a non-structured10-cm length scale from "no perception" to "high perception". The sensory descriptors were defined as: positives (fruity taste and aroma, acid taste, sweet taste and green color) and negatives (bitter, rancid, yeast taste and odor, and yellow color).

The following attributes, such as taste, color, aroma and general appreciation, were measured by an acceptability test, which was based on five points hedonic scores $(1=$ dislike to $5=$ like extremely). The evaluation panel was composed by twenty five individuals, males and females (aged from 21 to 45). For the Qualitative Descriptive Analysis (QDA), twelve panelists were selected from the 25 who participated in the hedonic test. They were trained in one hour session during two days a week for four weeks in order to determine by consensus the descriptors that best defined the sensory attributes of odor, taste and color of COFs. The reproducibility and reliability of their evaluations were measured for $p>0.05$ using the analysis of variance.

\subsection{Quality parameters}

Corn oil monitored by using peroxide values (PV) were determined by the iodometric assay (European Union, 1991), while acidity (g oleic acid per $100 \mathrm{~g}$ corn oil) and UV indices $\left(\mathrm{K}_{232}\right.$ and $\left.\mathrm{K}_{270}\right)$ were measured according to the European Union (EU) Reg. 61/2011 standard method. Spectrophotometric measurements were obtaining by using the HP spectrophotometer 4583 (USA).

\subsection{Total biophenols and vegetable pigments}

The total phenols in refined corn oil and COF samples were determined as indicated by Vázquez et al. (1973). Briefly, a methanol-water mixture (60:40) was used to extract all the phenolic compounds presented in the oil matrix. An adequate aliquot of this extract was treated with the Folin-Ciocalteau reagent and the absorbance was measured after $30 \mathrm{~min}$. The Total Phenolic Concentration (TFC) $\left(\mathrm{mg} \mathrm{kg}^{-1}\right)$ was determined using caffeic acid for the calibration standard. Chlorophylls were determined by the Cd 13d-55 spectrophotometric procedure (American Oil Chemists' Society, 1998). 


\subsection{Fatty acid composition}

The analysis of the fatty acid composition regarding the triacylglycerols was performed by Gas Chromatography (GC) after the derivatization into methyl esters by vigorous shaking of a solution of the oil in hexane with $0.4 \mathrm{~mL}$ of $2 \mathrm{~N}$ potassium hydroxide solution in methanol. The methyl esters were injected $(1 \mu \mathrm{L})$ in the injection port of an Agilent GC 4890 provided with a Flame Ionized Detector (FID), and the separation was done in a HP 5 (nonpolar, $30 \mathrm{~m} \times 0.53 \mathrm{~mm} \times 0.88 \mu \mathrm{m}$, bonded, cross-linked, 5\%-Phenyl-methylpolysiloxane) column using nitrogen as the carrier gas (flow $1 \mathrm{~mL} \mathrm{~min}{ }^{-1}$ ). The temperatures of injector and detector were $250{ }^{\circ} \mathrm{C}$ while the oven temperature was set at $210^{\circ} \mathrm{C}$. The identification was made by comparing the retention time of each peak with the signals of standard fatty acids, for the quantification the percentage of peak area.

\subsection{Determination of volatile compounds}

This procedure was adapted from Vichi et al. (2005). Solid-phase Microextraction (SPME) followed by GC were used to analyze the volatile compounds in the oil samples. $1.5 \mathrm{~g}$ of oil spiked with 4-methyl-2pentanol (as internal standard) to a concentration of $1.5 \mu \mathrm{g} \mathrm{g}^{-1}$ was placed in a $10 \mathrm{~mL}$ vials with a silicone septum. The SPME sampling was performed by exposing the DVB/Carboxen/PDMS fiber $(50 / 30 \mu \mathrm{m}, 2 \mathrm{~cm}$ long from Supelco Inc., Bellefonte, PA) for $30 \mathrm{~min}$ in the headspace of the sample maintained at $40{ }^{\circ} \mathrm{C}$; and then it was retracted into the needle and immediately transferred and desorbed for $1 \mathrm{~min}$ in the injection port of an Agilent GC 5890 Series equipped with FID. Compounds were separated on a Supelcowax-10 column (30 $\mathrm{m} \times 0.25 \mathrm{~mm} \times 0.25 \mu \mathrm{m}$, Supelco Inc., Bellefonte, PA) under the following conditions: injection port temperature at $260^{\circ} \mathrm{C}$; helium flow $0.8 \mathrm{~mL} / \mathrm{min}$; oven temperature ramp at $35^{\circ} \mathrm{C}$ for $10 \mathrm{~min}, 3{ }^{\circ} \mathrm{C} / \mathrm{min}$ up to $160{ }^{\circ} \mathrm{C}$ and then $15{ }^{\circ} \mathrm{C} / \mathrm{min}$ up to $200{ }^{\circ} \mathrm{C}$ (maintained for $5 \mathrm{~min}$ ). Volatile compounds were identified by comparison the retention times and mass spectra of standard substances (Sigma Aldrich) added to refined corn oil. The equipment used was an Agilent 5975C Series mass spectrometer (Agilent Technologies, USA) equipped with an electron ionization (EI+) detector and coupled to an Agilent GC 6850 Series; the capillary column was a DB-Wax $(30 \mathrm{~m} \times 0.25 \mathrm{~mm} \times 0.25 \mu \mathrm{m}$, J\&W Scientific, USA $)$. Helium was employed as carrier gas at a flow rate of $0.8 \mathrm{~mL} / \mathrm{min}$. The transfer line temperature was at $280{ }^{\circ} \mathrm{C}$ and the temperature of the ionization source and the quadrupole were at $230{ }^{\circ} \mathrm{C}$ and $150{ }^{\circ} \mathrm{C}$ respectively, with an electron multiplier voltage of $+941 \mathrm{~V}$.

In a preliminary study, $1.5 \mathrm{~g}$ of the original refined corn oil was spiked with $\alpha$-pinene and 1-penten-3-ol standards (Sigma-Aldrich, Spain) at $1.5 \mu \mathrm{g} \mathrm{g}^{-1}$ concentrations each one along with the same concentration of the internal standard. The quantification of these compounds was performed as described before, and recoveries between $85 \%$ and $105 \%$ were obtained.

The identification was carried out by mass spectrometry and later checked with available standards. To identity the volatile compounds, the comparison of their mass spectra data with the information of Wiley Data Base and NBS75k libraries was determined. The volatile compounds were also identified using the Relative Retention Times (RRT) of the standards with respect to the internal standard.

\subsection{Oxidative stability test}

The oxidative stability was assessed under accelerated conditions using the Rancimat 679 equipment (Methrom, Switzerland) employing $3.5 \mathrm{~g}$ oil samples at $120^{\circ} \mathrm{C}$ and with an air flow of $20 \mathrm{~L} \mathrm{~h}^{-1}$. Long term storage at $25 \pm 2{ }^{\circ} \mathrm{C}$ was also employed, in this experiment $100 \mathrm{~g}$ of refined and aromatized oils were weighed in triplicate in $250 \mathrm{~mL}$ beakers, capped with aluminum foil sheets and randomly located inside a thermostatic chamber. Periodically, $2 \mathrm{~g}$ aliquots were taken to measure the $\mathrm{PV}$ until reach a limit value of $10 \mathrm{meq}_{2} \mathrm{~kg}^{-1}$. 


\subsection{Statistical analysis}

Sensory and chemical data were analyzed using the IBM SPSS Statistics 22 software. Significance among samples was performed using One-Way ANOVA and comparisons between means were performed by Tukey's test (Bower, 2013). Differences were considered significant at $p<0.01$.

\section{Results and discussion}

\subsection{Quality indices and chemical composition of COF's}

Table 1 shows the main quality indices according to the Codex Alimentarius (Food and Agriculture Organization of the United Nations, 1981) for refined vegetable oils. The addition of $7 \%$ of orange raised the PV from 3.46 to 4.15 meq $\mathrm{O}_{2} \mathrm{~kg}^{-1}$, while the lemon did not affect PV. However, in all cases the PV were below the limit value for good quality edible oils $\left(5\right.$ meq $\left.\mathrm{O}_{2} \mathrm{~kg}^{-1}\right)$. The presence of organic acids, such as citric acid, in both fruits may be responsible for increasing oil acidity, which was proportional to the amount of fruit added.

Table 1. Quality Indices of corn oil unflavored and flavored with lemon and orange.

\begin{tabular}{ccccc}
\hline Treatments & $\begin{array}{c}\text { PV } \\
\left(\mathbf{m e q} \mathbf{O}_{\mathbf{2}} \mathbf{~ k g}^{-1}\right)\end{array}$ & $\begin{array}{c}\text { Acidity } \\
(\mathbf{\%} \text { Oleic Acid) }\end{array}$ & $\mathbf{K}_{\mathbf{2 3 2}}$ & $\mathbf{K}_{\mathbf{2 7 0}}$ \\
\hline $\mathrm{T}_{0}($ Corn oil only) & $3.46 \pm 0.02^{\mathrm{a}}$ & $0.28 \pm 0.01^{\mathrm{c}}$ & 2.2134 & 0.2510 \\
\hline $\mathrm{T}_{1}($ Lemmon 3\%) & $3.45 \pm 0.02^{\mathrm{a}}$ & $0.33 \pm 0.01^{\mathrm{c}}$ & 2.3567 & 0.2372 \\
\hline $\mathrm{T}_{2}($ Lemmon 5\%) & $3.46 \pm 0.01^{\mathrm{a}}$ & $0.35 \pm 0.01^{\mathrm{c}}$ & 2.3562 & 0.2290 \\
\hline $\mathrm{T}_{3}($ Lemmon 7\%) & $3.46 \pm 0.01^{\mathrm{a}}$ & $0.39 \pm 0.01^{\mathrm{c}}$ & 2.3771 & 0.2500 \\
\hline $\mathrm{T}_{4}($ Orange 3\%) & $3.99 \pm 0.02^{\mathrm{b}}$ & $0.41 \pm 0.01^{\mathrm{c}}$ & 2.2893 & 0.2347 \\
\hline $\mathrm{T}_{5}($ Orange 5\%) & $4.01 \pm 0.01^{\mathrm{b}}$ & $0.40 \pm 0.02^{\mathrm{c}}$ & 2.3329 & 0.2436 \\
\hline $\mathrm{T}_{6}($ Orange 7\%) & $4.15 \pm 0.02^{\mathrm{d}}$ & $0.43 \pm 0.02^{\mathrm{c}}$ & 2.3005 & 0.2313 \\
\hline
\end{tabular}

Means with the same letters did not differ at $p<0.01$. Means with different letters differ at $p<0.01$.

The addition of fruits to the refined corn oil had no effect on the conjugated dienes and trienes. These compounds, which are derived from oxidation reactions on PUFAs, are measured through spectrophotometric indices $\mathrm{K}_{232}$ and $\mathrm{K}_{270}$, and the results showed the absence of statistical significant differences between the refined oil and its mixtures, suggesting that the maceration during one month at ambient temperature did not favor the oil oxidation.

The fatty acids profiles of the refined and flavored corn oils (Table 2) showed the presence of mono (28\%) and polyunsaturated (57\%) fatty acids, while the saturated fatty acids were present in minor proportions $(15 \%)$. The composition of fatty acids is responsible for the susceptibility of corn oil to oxidation reactions, being necessary an addition of antioxidants, for example, natural or synthetic phenols to improve shelf life.

Table 2. Fatty acid composition of the refined corn oil.

\begin{tabular}{cc}
\hline Fatty Acid & Concentration $\left(\mathbf{g} \mathbf{~ 1 0 0 ~ \mathbf { ~ g } ^ { - 1 } )}\right.$ \\
\hline Myristic & 1.6 \\
\hline Palmitic & 13.1 \\
\hline Stearic & 0.3 \\
\hline Oleic & 28.0 \\
\hline Linoleic & 55.0 \\
\hline Linolenic & 2.0 \\
\hline
\end{tabular}

The low concentrations of biophenols and pigments (Table 3) in the commercial corn oil is the result of the refining process, specifically during the physical refining step where adsorbent materials are employed to remove all the colored substances presented in crude vegetable oils (Navas, 2016). The addition of large 
amounts of fruits increased the concentrations of biophenols between 32.80 to $46.43 \mathrm{mg} \mathrm{kg}^{-1}$, being observed higher amount when orange was added, these compounds may play an important role for human health, because of their recognized antioxidant and antiradical effects (Murillo et al., 2013), which may help for preventing hearth diseases, atherosclerosis and even cancer (Gee \& Johnson, 2001).

Table 3. Pigments, biophenols and Rancimat stability for unflavored and flavored oils.

\begin{tabular}{cccc}
\hline Treatments & $\begin{array}{c}\text { Chlorophylls } \\
\left(\mathbf{m g ~ k g}^{-1}\right)\end{array}$ & $\begin{array}{c}\text { Biophenols } \\
\left(\mathbf{m g ~ k g}^{-1}\right)\end{array}$ & $\begin{array}{c}\text { Oxidative } \\
\text { Stability (h) }\end{array}$ \\
\hline $\mathrm{T} 0$ & $0.62 \pm 0.02^{\mathrm{a}}$ & $1.00 \pm 0.25^{\mathrm{c}}$ & $4.5 \pm 0.5^{\mathrm{e}}$ \\
\hline $\mathrm{T} 1$ & $1.45 \pm 0.05^{\mathrm{b}}$ & $32.8 \pm 5.8^{\mathrm{d}}$ & $4.5 \pm 0.5^{\mathrm{e}}$ \\
\hline $\mathrm{T} 2$ & $1.54 \pm 0.05^{\mathrm{b}}$ & $33.7 \pm 5.0^{\mathrm{d}}$ & $4.6 \pm 0.5^{\mathrm{e}}$ \\
\hline $\mathrm{T} 3$ & $1.56 \pm 0.05^{\mathrm{b}}$ & $34.1 \pm 4.9^{\mathrm{d}}$ & $4.6 \pm 0.5^{\mathrm{e}}$ \\
\hline $\mathrm{T} 4$ & $0.79 \pm 0.02^{\mathrm{a}}$ & $36.6 \pm 2.0^{\mathrm{d}}$ & $4.5 \pm 0.5^{\mathrm{e}}$ \\
\hline $\mathrm{T} 5$ & $0.76 \pm 0.01^{\mathrm{a}}$ & $45.4 \pm 2.2^{\mathrm{d}}$ & $4.6 \pm 0.5^{\mathrm{e}}$ \\
\hline $\mathrm{T} 6$ & $0.76 \pm 0.02^{\mathrm{a}}$ & $46.4 \pm 4.3^{\mathrm{d}}$ & $4.6 \pm 0.5^{\mathrm{e}}$ \\
\hline
\end{tabular}

Means with the same letter did not differ at $p<0.01$. Means with different letters differ at $p<0.01$.

On the other hand, a slight increase in the chlorophyll content was measured in the lemon in which was added the corn oil, due to the dissolution in the oil matrix of the chlorophyll pigments originally presented in the lemon shells (Martínez et al., 2013), therefore, providing to those mixtures their green colors. The corn oil flavoured by orange scent showed the same pale yellow color of the original refined corn oil, which is consistent with the low concentration of chlorophyll presented in the orange fruit.

The oxidative stability test of flavoured oils has begun from 4.51 to $4.64 \mathrm{~h}$, being similar to the stability of the corn oil without the fruits $(4.49 \mathrm{~h})$. In this work, the oil stability was assessed by the accelerated Rancimat test, which employs strong conditions of temperature $\left(120^{\circ} \mathrm{C}\right)$ and air flows $\left(20 \mathrm{~L} \mathrm{~h}^{-1}\right)$ in order to accelerate the reactions between the unsaturated fatty acids and the Reactive Oxygen Species (ROS).

Several studies on the stability of vegetable oils added with natural antioxidants have been demonstrated that the Rancimat test may not be the best procedure to evaluate the oil stability, because the test conditions benefit the production of highly ROS which may react with the double bonds of the fatty acids faster than with the antioxidants molecules, with a subsequent increase in the PV.

Therefore, the natural phenols extracted from the lemon or orange fruits seem not to be effective to protect the corn oil from the ROS under Rancimat test conditions. For that reason, a second evaluation was performed under long term storage conditions at ambient temperature $\left(25 \pm 2{ }^{\circ} \mathrm{C}\right)$, requiring 95,126 and 124 days to reach a PV of 10 meq $\mathrm{O}_{2} \mathrm{~kg}^{-1}$ regarding the refined lemon and orange corn oils that were added respectively, showing that the biophenols of these fruits can effectively protect the oil from oxidation reactions.

\subsection{Volatile compounds}

During the refining process, the crude corn oil has been subjected to a deodorization step, in order to eliminate those substances that may originate unpleasant odors. The commercial refined corn oil employed in this study contained very low concentrations of hexanal, 2-methylbutanal and butanal, which could be formed by the storage conditions. However, these aldehydes were not detected in the volatile profiles of aromatized oils, probably because they were masked during the quantification by the other volatile compounds released by the macerated fruits in higher concentrations.

It was also found that the headspace volatile profile of corn oil was strongly affected by adding lemon and orange. The Volatile Organic Compounds (VOCs) present in these fruits are synthesized during ripening and they can migrate to the oily matrix, insofar as several of these organic compounds have been identified (Table 4), including alcohols, hydrocarbons, terpenes and esters. 
Table 4. Volatile Organic Compounds $\left(\mu \mathrm{g} \mathrm{g}^{-1}\right)$.

\begin{tabular}{|c|c|c|c|c|c|c|c|}
\hline $\begin{array}{c}\text { Compound } \\
\text { (Sensory Descriptor) }^{1,2} \\
\end{array}$ & T0 & T1 & $\mathbf{T 2}$ & T3 & T4 & T5 & T6 \\
\hline \multicolumn{8}{|l|}{ Aldehydes } \\
\hline Hexanal & 0.33 & $\mathrm{Nd}$ & $\mathrm{Nd}$ & $\mathrm{Nd}$ & $\mathrm{Nd}$ & $\mathrm{Nd}$ & $\mathrm{Nd}$ \\
\hline 2-Methylbutanal & 0.17 & $\mathrm{Nd}$ & $\mathrm{Nd}$ & $\mathrm{Nd}$ & $\mathrm{Nd}$ & $\mathrm{Nd}$ & $\mathrm{Nd}$ \\
\hline Butanal & 0.08 & $\mathrm{Nd}$ & $\mathrm{Nd}$ & $\mathrm{Nd}$ & $\mathrm{Nd}$ & $\mathrm{Nd}$ & $\mathrm{Nd}$ \\
\hline \multicolumn{8}{|l|}{ Hidrocarbons } \\
\hline 2-Methyl-1-heptene & & 0.59 & 0.61 & 0.63 & $\mathrm{Nd}$ & $\mathrm{Nd}$ & $\mathrm{Nd}$ \\
\hline \multicolumn{8}{|l|}{ Alcohols } \\
\hline Ethanol & & 159.4 & 159.7 & 163.1 & 13.85 & 14.51 & 14.77 \\
\hline 1-Penten-3-ol & & 11.21 & 11.75 & 11.99 & $\mathrm{Nd}$ & $\mathrm{Nd}$ & $\mathrm{Nd}$ \\
\hline Linalool (Citrus) & & 4.83 & 5.01 & 5.17 & 1.68 & 1.76 & 1.80 \\
\hline Hexanol (Fruity) & & 20.38 & 21.34 & 21.79 & 0.21 & 0.22 & 0.23 \\
\hline \multicolumn{8}{|l|}{ Terpenes } \\
\hline$\alpha$-Pinene (Fruity) & & 1.64 & 2.15 & 2.76 & 0.63 & 0.66 & 0.68 \\
\hline$\beta$-Pinene (Musty-Green) & & 3.17 & 3.30 & 3.39 & 0.11 & 0.12 & 0.12 \\
\hline$\alpha$-Phellandrene (Fruity) & & 10.65 & 11.18 & 11.42 & 2.54 & 2.67 & 2.72 \\
\hline$\beta$-Terpinene & & 1.92 & 2.10 & 2.16 & $\mathrm{Nd}$ & $\mathrm{Nd}$ & $\mathrm{Nd}$ \\
\hline$\gamma$-Terpinene (Citrusy) & & 143.5 & 150.6 & 153.6 & 0.25 & 0.26 & 0.27 \\
\hline Sabinene & & 0.58 & 0.61 & 0.63 & $\mathrm{Nd}$ & $\mathrm{Nd}$ & $\mathrm{Nd}$ \\
\hline$\alpha$-Terpinolene & & 8.11 & 8.41 & 8.68 & 0.28 & 0.29 & 0.30 \\
\hline Caryophyllene (Musty-Green) & & 12.30 & 12.91 & 13.16 & 2.70 & 2.84 & 2.89 \\
\hline Cymene (Lemon) & & 8.14 & 8.53 & 8.72 & 0.54 & 0.57 & 0.58 \\
\hline Borneol & & 10.58 & 11.11 & 11.32 & 0.11 & 0.116 & 0.12 \\
\hline$\beta$-Mircene (Musty) & & $\mathrm{Nd}$ & $\mathrm{Nd}$ & $\mathrm{Nd}$ & 0.22 & 0.23 & 0.24 \\
\hline Limonene (Citrusy) & & 437.5 & 458.9 & 467.6 & 181.1 & 190.1 & 193.7 \\
\hline \multicolumn{8}{|l|}{ Ester } \\
\hline Ethylacetate & & $\mathrm{Nd}$ & $\mathrm{Nd}$ & $\mathrm{Nd}$ & 0.25 & 0.26 & 0.27 \\
\hline
\end{tabular}

$\mathrm{Nd}=$ Below than $0.05 \mu \mathrm{g} \mathrm{g}{ }^{-1} .{ }^{1}$ Hognadottir \& Rouseff (2003). ${ }^{2}$ Lin \& Rouseff (2001).

Ethanol was the most abundant compound in both corn oils, its presence would be associated with the conversion of the sugars to alcohol in an incipient stage of fermentation of the fruits, which is not easily detected by its odor, however, it can be quantified by the analytical procedure employed here.

Other organic compounds also presented in the volatile fraction were the penten-3-ol, linalool and hexanol, accompanied by higher concentrations of flavored oils in lemon than those found in the oil with orange. The only ester identified in the orange FCO was the ethylacetate. These compounds can contribute to the flavour of the aromatized oils. For instance, linalool and hexanol have floral aromas and citrus have fruit aromas detected in COF.

Different terpenes were identified in the lemon and orange COF's being similar to previous studies on chemical composition of their essential oils (Allegrone et al., 2006; Dharmawan et al., 2007). Among them, the limonene was, by far, the most abundant compound when lemon was employed. This terpene along with $\gamma$-terpinene, $\alpha$-pinene, $\beta$-pinene, cariophyllene, $\alpha$-felandrene are the responsible for citrus and green flavors of the "lemon COF" (Lin \& Rouseff, 2001).

A similar qualitative composition was found for the "orange COF", although lower concentrations were determined, suggesting that the orange maceration in corn oils yield aromatized oils with a lower richness in volatile terpenes, which may affect its sensory characteristics.

\subsection{Sensory analysis}

According to Navas (2013) and Krist et al. (2006) the addition of spices, fruits and herbs to oils had an important impact in their sensory characteristics, giving strong flavors and tastes. This study confirmed that corn oil can be used as a solvent to dissolve several terpenes contained in the citrus fruits, which can give to 
the oils their particular sensory characteristics, which may improve its acceptability with a wide range of applications, from frying foods to oils for salad dressings.

The COF's sensory profiles (Figure 1) demonstrated that "lemon-COF" reached high scores for the sour and fruity taste qualities, probably due to the higher concentrations of terpenes such as limonene, $\gamma$-terpinene and $\alpha$-felandrene by creating citrus andfruity sensations. This may explain the lower scores for "orange COF" for the same attributes, seeing that the same terpenes were present in minor concentrations.

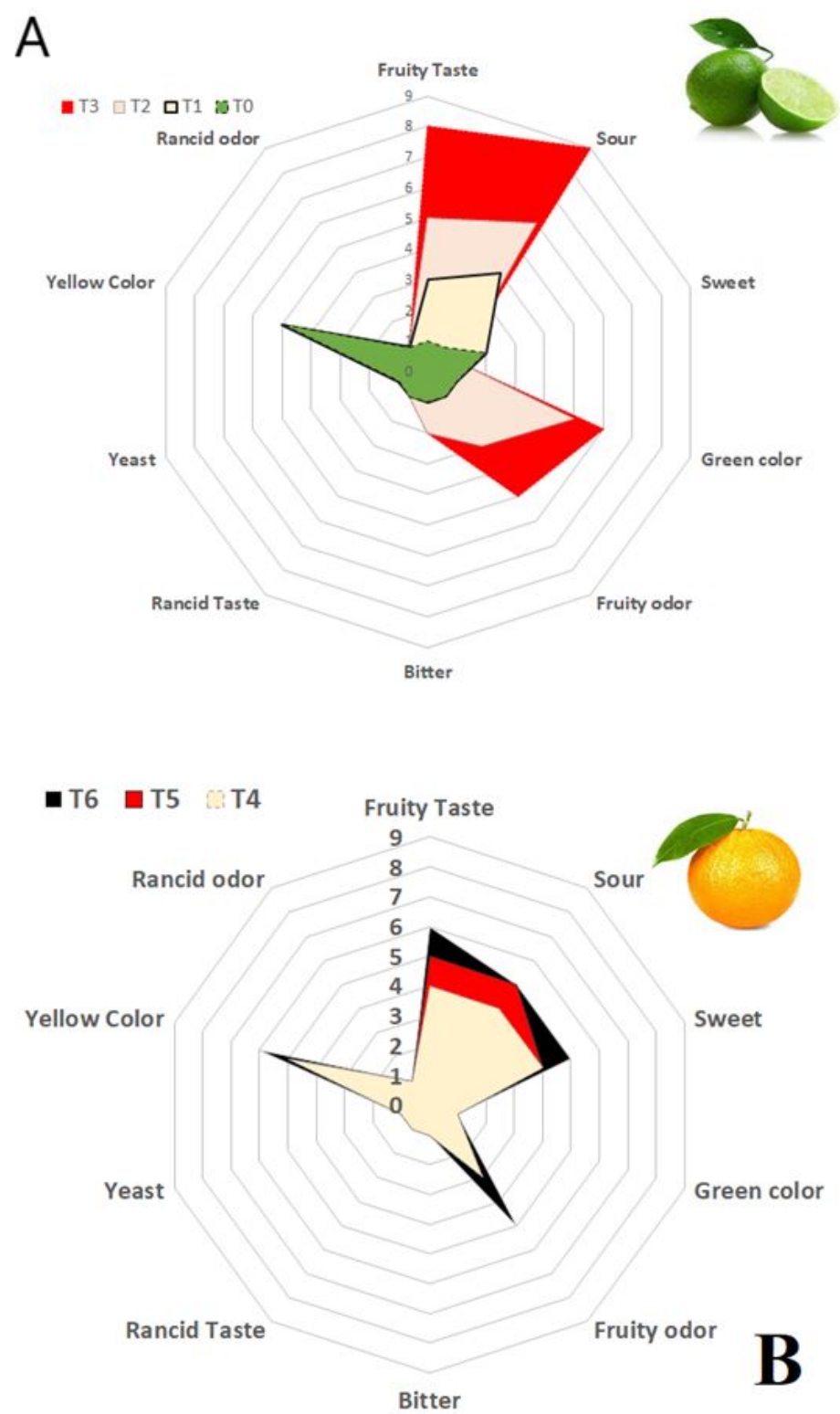

Figure 1. Sensory profiles of corn oil flavoured by (A) lemon and (B) orange.

Although the addition of increased amounts of lemon or orange fruits to the refined corn oil did not increase the volatiles concentrations, nevertheless, the sensory analysis indicated an improving in the perceptions of $\mathrm{COF}$ in flavor and taste, with scores for the positive attributes (fruity, sour, sweet green color) higher than those found for the negative attributes (bitter, yeast, rancid). For instance, in "lemon COF", the most important attributes were fruity and sour tastes, followed by fruity odor, which can be related to the 
presence of the terpenes in the volatile profile. Negative attributes reached very low scores suggesting a very good acceptance of this COF.

On the other hand, the same qualitative description could be made for "orange COF", the minor scores for the positive attributes was consistent with low concentrations of terpenes in this volatile profile. In general, the addition of orange also improved the perception of positive attributes in the aromatized corn oil.

The Cluster analysis (Figure 2) indicated two groups of homogeneous attributes for the non-aromatized corn oil, one that includes nine of 10 original attributes, and the second group was formed only by the attribute "yellow color", which demonstrated that in the refined oil, sensory notes such as flavor or taste attributes were absent. The sensory profiles are clearly modified by the addition of lemon or orange as described before. For instance, the dendrogram for "lemon COF" produced two main groups, one which included only positive attributes and the other only the negatives. The green color, owing to the dissolution of chlorophyll in the oil matrix, was included in the group of positive attributes along with the fruity sensations.
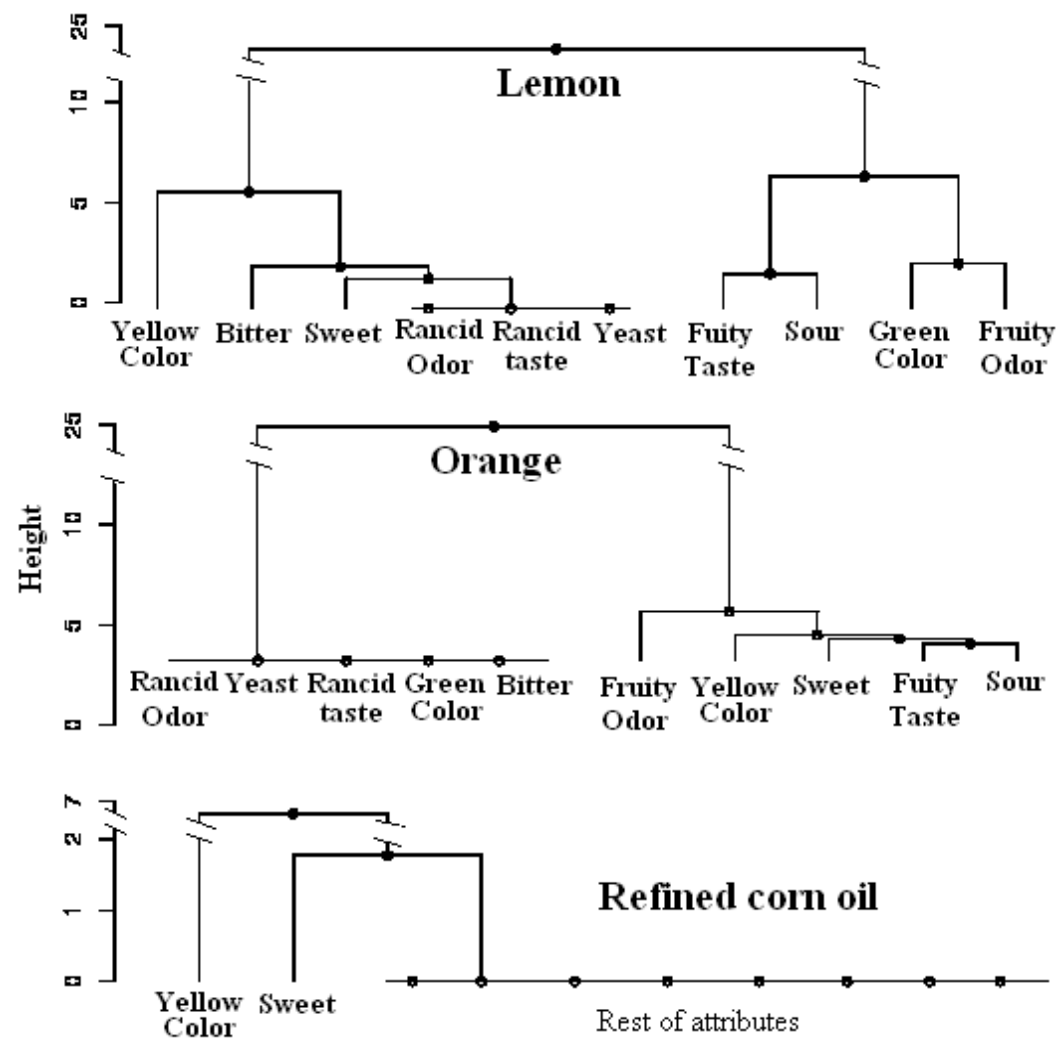

Figure 2. Dendrograms for the Quantitative Descriptive Analysis (QDA) regarding sensory evaluation of COFs.

On the other hand, the "orange COF" dendrogram also grouped the sensory attributes in two main homogeneous groups. Few differences regarding the lemon dendrogram could be observed; and in this case, the sweet taste was included in the positive attributes group along with the yellow color. The presences of green or yellow colours as positive attributes indicated that color played an important role for the sensory evaluation by providing positive responses for the evaluation panel members.

The acceptability of the refined and COF oils were measured with the hedonic scale, giving median scores for the refined corn oil between 3.0 and 3.2 (Figure 3), representing an acceptability which was neither negative nor positive for the sensory attributes such as color, odor and taste. The "lemon or orange COF's" 
represented better scores for all sensory attributes, being important to note that byincreasing fruits present, the best results corresponded to $7 \%$ of fruit added.

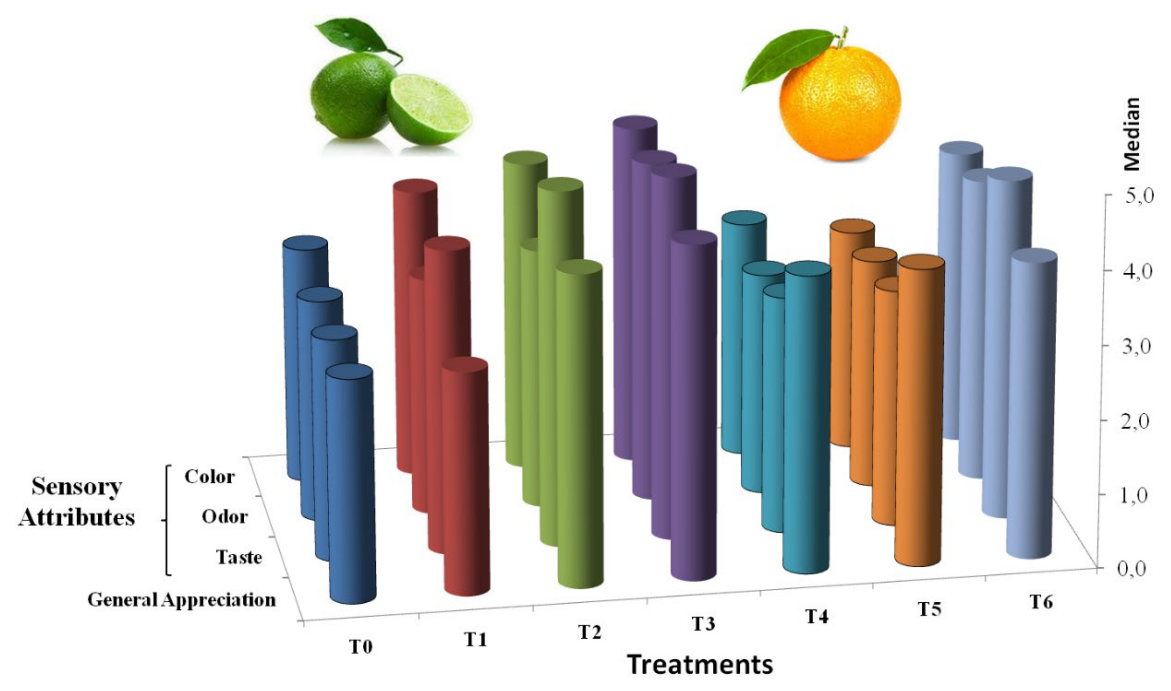

Figure 3. Median of hedonic scores for treatments and attributes.

The "general appreciation" item was considered as a global subjective evaluation of the oil sensory qualities, the good acceptability by the panel was evidenced by the high values in all treatments.

\section{Conclusions}

The addition of lemon or orange to the refined corn oil could modify its quality parameters, by adding biophenols with potential health benefits and volatile aroma compounds which may improve the sensory qualities. The flavouring with these fruits provided a much appreciate qualities for these oils, whereas the lemon or orange COF were better perceived than the refined oil. In addition, the aromatized corn oil may have wide range of applications, for instance, meats and salads as well as to make cakes or sweets with pleasant citrus sensations.

\section{References}

Allegrone, G., Belliardo, F., \& Cabella, P. (2006). Comparison of volatile concentration in hand-squeezed juices of four different lemon varieties. Journal of Agricultural and Food Chemistry, 54(5), 1844-1848. PMid:16506842. http://dx.doi.org/10.1021/jf051206s

American Oil Chemists' Society - AOCS. (1998). Official methods and recommended practices of the American Oil Chemists Society (5th ed.). Champaing: AOCS Press.

Bower, J. (2013). Statistical methods for food science: Introductory procedures for the food practitioner (2nd ed.). Chichester: John Wiley \& Sons. http://dx.doi.org/10.1002/9781118541593

Dharmawan, J., Kasapis, S., Curran, P., \& Johnson, J. R. (2007). Characterization of volatile compounds in selected citrus fruits from Asia. Part I: Freshly-squeezed juice. Flavour and Fragrance Journal, 22(3), 228-232. http://dx.doi.org/10.1002/ffj.1790

European Union. Comision of the European Communities - CEE. (1991). Regulation 2568/1991. Official Journal of European Communities, Bruxelas, nº L.248/9.

Food and Agriculture Organization of the United Nations - FAO. (1981). CODEX STAN 19-1981 (Rev. 2-1999): Norma del Codex para grasas y aceites comestibles no regulados por normas individuales (pp. 1-5). Washington: FAO.

Foster, B., Arnason, J., \& Briggs, C. (2005). Natural health products and drug disposition. Annual Review of Pharmacology and Toxicology, 45(1), 203-226. PMid:15822175. http://dx.doi.org/10.1146/annurev.pharmtox.45.120403.095950

Gee, J., \& Johnson, I. (2001). Polyphenolic compounds: Interactions with the gut and implications for human health. Current Medicinal Chemistry, 8(11), 1245-1255. PMid:11562264. http://dx.doi.org/10.2174/0929867013372256 
Hognadottir, A., \& Rouseff, R. (2003). Identification of aroma active compounds in orange essence oil using gas chromatography-olfactometry and gas chromatography-mass spectrometry. Journal of Chromatography. A, 998(1-2), 201-211. PMid:12862384. http://dx.doi.org/10.1016/S0021-9673(03)00524-7

Issaoui, M., Flamini, G., Hajaij, M. E., Cioni, P. L., \& Hammami, M. (2011). Oxidative evolution of virgin and flavored olive oils under thermo-oxidation processes. Journal of the American Oil Chemists' Society, 88(9), 1339-1350. http://dx.doi.org/10.1007/s11746-011-1800-5

Kelebek, H., Selli, S., Canbas, A., \& Cabaroglu, T. (2009) HPLC determination of organic acids, sugar, phenolic compositions and antioxidant capacity of orange juice and orange wine made from a Turkish cv. Kosan. Micro Chemical Journal, 91(2), 187192. http://dx.doi.org/10.1016/j.microc.2008.10.008

Krist, S., Stuebiger, G., Bail, S., \& Unterweger, H. (2006). Detection of adulteration of poppy seed oil with sunflower oil based on volatiles and triacylglycerol composition. Journal of Agricultural and Food Chemistry, 53(17), 8310-8316. PMid:16910734. http://dx.doi.org/10.1021/jf060500x

Kuljarachanan, T., Devahastin, S., \& Chiewchan, N. (2009). Evolution of antioxidant compounds in lime residues during drying. Food Chemistry, 113(4), 944-949. http://dx.doi.org/10.1016/j.foodchem.2008.08.026

Lin, J., \& Rouseff, R. (2001). Characterization of aroma-impact compounds in cold-pressed grapefruit oil using time-intensity GC-olfactometry and GC-MS. Flavour and Fragrance Journal, 16(6), 457-463. http://dx.doi.org/10.1002/ffj.1041

Martínez, O., Román, M., Gutierrez, E., Medina, G., \& Flores, O. (2013). Caracterización sensorial de fibras de algunas frutas comunes en Colombia. Revista Colombiana de Ciencias Químico - Farmacéuticas, 10(2), 9-19.

Murillo, J., García, L., \& Carrasquero, A. (2013). Aplicación de la quimioluminiscencia luminol-perborato-Co(II) para la enseñanza de Las relaciones estructura-reactividad en moléculas orgánicas. Paradigma, 34(2), 93-108.

Navas, P. B., Carrasquero-Durán, A., \& Flores, I. (2006). Effect of black tea, garlic and onion on corn oil stability and fatty acid composition under accelerated oxidation. International Journal of Food Science \& Technology, 41, 243-247. 10.1111/j.13652621.2005.01056.x

Navas, P. (2013). Volatile aroma components of cool pressed virgin oils from several Venezuelan. Journal of Food and Dairy Technology, 1(2), 13-17.

Navas, P. (2016). Adición de compuestos bioactivos a un aceite refinado de maíz condimentado con especias. Saber, 28(2), 257-264.

Pérez-Najera, V., Lugo-Cervantes, E., Gutiérrez-Lomelí, M., \& Del-Toro-Sánchez, C. (2013). Extracción de compuestos fenólicos de la cascara de lima (Citrus limetta Risso) y determinación de su actividad antioxidante. Biotecnia, 15(3), 18-23. http://dx.doi.org/10.18633/bt.v15i3.153

Vázquez, A., Janer, C., \& Janer, M. (1973). Determinación de los polifenoles del aceite de oliva. Grasas y Aceites, 24(6), 350357.

Vichi, S., Pizzale, L., Conte, L., Buxaderas, S., \& Lopez-Tamames, E. (2005). Simultaneous determination of volatile and semivolatile aromatic hydrocarbons in virgin olive oil by headspace solid-phase microextraction coupled to gas chromatography/mass spectrometry. Journal of Chromatography A, 1090(1-2), 146-154. PMid:16196143. http://dx.doi.org/10.1016/j.chroma.2005.07.007 